\title{
MAKING MACHINIMA: animation, games and multimodal participation in the media arts
}

Andrew Burn

ABSTRACT

In the project discussed in this article, 30 11-year-olds made an animated film in the machinima style, influenced by both film and game culture, and using a 3-D animation software tool, Moviestorm. The processes and products of the project will be analysed using a social semiotic/multimodal approach, exploring the social interests behind the integration of visual design, music, voice acting, story-writing and animation which characterise the project. The outcomes suggest a need to move beyond established thinking and practice in media literacy practice and research in three ways. First, we need to develop moving image education to recognise new genres and cultures. Second, we need to recognise that such productions are intensely multimodal, involving music, drama, story-writing and visual design. Third, such projects demand connected pedagogy across media, literacy, music, drama, computer science and art.

\section{INTRODUCTION}

Media literacy is a contested notion, in Europe, in the US, and globally. In my own context, it is closely allied with a model of media education built around a conceptual framework of media institutions, texts and audiences, a model best-known in David Buckingham's version (2003).

My own conception, while close to Buckingham's (and indebted to his) is a little different. For one thing, it incorporates an emphasis on the poetics of the media as well as the rhetorics. For another, it incorporates a social semiotic-multimodal notion of media texts. It is elaborated fully in Burn and Durran (2007), along with a series of case studies exemplifying its various features.

The project described and analysed in this article - 11-year-old schoolchildren making machinima films - will also exemplify aspects of this model. As a film-making project, however, it sits within the contexts of film education and film literacy, which can in my view be seen as a subset of a more general conception of media literacy. The remainder of this article will consider the nature of film education, then, before going on to outline a multimodal theory of film; and finally to explore data from the project in focus.

\section{FILM EDUCATION}

Film education, like its parent discipline Film Studies, is Janus-faced. On the one hand, it experiences a pull towards film as heritage culture, to established cinematic canons, to the national archives of whichever country it finds itself in, and to the aesthetic of arthouse cinema. The general impulse of educators here is broadly comparable to that of art educators more generally: an induction into certain kinds of cultural judgment, an appreciative stance towards cultural heritage, a belief in the arts as an important part of civil society. The semiotic realisation of this impulse is a theoretical and practical commitment to the century-old 'grammar' or 'language' of 
film, to use the linguistic metaphors developed by the film semioticians of the midtwentieth century (such as Barthes, 1978; Metz, 1974).

On the other hand, film education looks to the future. It exploits the (by now not so) new digital authoring technologies of composition - non-linear editing tools - and distribution - upload, sharing, social media. It espouses popular cinema as well as arthouse: a recent European study found that film educators in member states included Hollywood as well as national, European and world cinema in their ideal curricula (Reid et al, 2012). The impulse of educators here is to promote learner agency and creativity (Potter, 2012), and to build on their engagement with film outside school. The semiotic realisations of this impulse are the evolving frameworks for the analysis of media language as digital code (eg Manovich, 1998), digital video as fluid chronotope (eg Gibbons, 2010), and digital video production as multimodal (eg Burn, 2013).

Taken together, this complex and often contradictory enterprise provokes a number of questions, three of which will be addressed in this article. The first is to do with culture. How is film culture changing: what new genres, judgments, affiliations are appearing? How are they apparent in the lives of young people?

The second is semiotic. How is the century-old language of film both persisting and transforming? How is it learned and employed by young people? What frameworks do educators need to teach film in the twenty-first century? What differences do the digital technologies of the moving image, in filming, editing and distribution, afford?

The third is curricular. Where, given both the historic nature of film as well as its emergent features, does film education best fit in school curricula? Or, to put it differently, what kind of alternative curriculum would enable film, along with the arts in general, to flourish in schools?

To address these questions, I want to discuss a recent film-making project with 11 year-old students in a school in the UK ${ }^{1}$. The project, a research and practice collaboration, was constructed to explore the relatively new genre of machinima, a portmanteau of machine-cinema, a form of animation derived from videogames and virtual worlds (Kelland et al, 2005). We did not expect the pupils to be aware of this new art-form - and indeed, only three children in the group recognised the word machinima. However, given the close association of the genre with computer games, we did expect some familiarity to be shown with certain semiotic and cultural properties of machinima; and again, this proved to be the case. For the record, the group consisted of 60 children: two mixed-ability classes of 30 . The school was a four-form entry 11-16 comprehensive, with 600 on roll. It served a mixed housing area, including a large council estate in East Cambridge. The school had faced significant problems with falling rolls and low academic outcomes, and had been placed in special measures by Ofsted ${ }^{2}$ and been under threat of closure by the local authority. Recently, it had hard-federated with a successful neighbouring school; intake was now at full capacity and results improving year on year. Though improving, its pupils attainment was still judged as 'low' in its last OfSted report,

\footnotetext{
${ }^{1}$ The project, entitled Montage, Mash-up, Machinima, was a collaboration between the Institute of Education, University of London, the University of Leeds, and the British Film Institute. It was conducted in 2012, and funded by First Light.

${ }^{2}$ The UK government's schools inspection service
} 
which also reported that "A higher than average proportion of students is from minority ethnic backgrounds and a much higher than average proportion of students speak English as an additional language. The number of students with special educational needs and/or disabilities is higher than the national average and makes up over a third of the school's cohort."

The project began with a day visit to the Arts cinema in Cambridge, the Arts Picturehouse, to show the students examples of machinima, since the genre was largely unfamiliar to them. It continued with a whole day session for them to get accustomed to the software, Moviestorm ${ }^{3}$, learning how to build simple sets, animate characters, and manage camera angles.

The next phase consisted of six weeks with a double period (100 minutes) per week. This began with construction of the story. The first group all contributed ideas orally, building up a story collaboratively-created under the supervision of the film-maker, Martin Sercombe. The story was of a teenage computer games geek, Jeff, who one day finds himself inside his own game, where he meets a green alien called $\mathrm{Dr} \mathrm{T}$. They visit Ancient Egypt, meet Cleopatra, and Jeff has to prevent Dr T from carrying out an evil bid for world domination.

The second group wrote stories as pitches for the film. One girl's story was chosen, and adapted into a script by the film-maker, for the group's film, The Moonstone. It told the tale of a teenage girl, Lily, whose parents were lost in a plane crash. She sets out to find them with her grandmother and a strange Indian guide. He turns out to be a 'good' werewolf, locked in combat with an evil werewolf. Lily helps him overcome his curse, beat the evil counterpart, and find her parents.

The next phase of the project involved specialist design. The children volunteered for four different groups: set design, character design, voice acting, and music. The assets produced by the groups were made available on the computer network for the next phase.

Finally, the class worked in pairs, each pair taking responsibility for a short section of the film. This involved drawing on the shared assets and using the Moviestorm software to animate the characters through the action, attach dialogue, construct shots and camera angles, and generally produce their section to the best of their ability. In the penultimate session, they looked at a rough cut, made critical comments on their own and each others' film sections, then worked for a whole day on a final session to edit and improve their film. The films were then edited together and the music added.

\section{DESIGNING IN THE KINEIKONIC MODE}

The kineikonic mode is a designation for the moving image as a multimodal form (Burn \& Parker, 2003; Burn, 2013). Kineikonic is a portmanteau of the Greek words for move and image - kinein and eikon. While this theory draws on many of the classic conceptions of filming and editing as semiotic processes (eg Metz, 1974, Barthes, 1978, Bordwell \& Thompson, 2001), it re-casts them as orchestrating modes: framing structures which construct spatial and temporal shapes around the

\footnotetext{
${ }^{3}$ Moviestorm is a 3-D animation tool based on the practice of machinima: www.moviestorm.com
} 
sounds and images produced by other modes (embodied action, speech, music, architecture, and so on), conceived of here as contributory modes.

In animated films, this multimodal composition happens in a specific way. To begin with, animation can be seen within a particular history of the moving image. It does not belong to the narrative which sees early film either as documentary record of life, as the Lumière Brothers' celebrated train sequence, or as realist drama, as in early stage adaptations, both of which are rooted in a referential ontology descended from the photograph as a copy of the world, a sign without code. Rather, it belongs to the narrative begun by (amongst others) Georges Méliès, whose fantastic collages and narratives emerge from an anti-realist ontology of dream, fantasy, magic, illusion, descending from the photograph as impossible image. A well-known example is the Victorian Cottingley fairies photographs which so deceived Conan Doyle.

This trajectory of the moving image has its place in arthouse cinema, which proceeds through the surrealist experiments of Dali and Buñuel to the experimental laminations and frame-play of Peter Greenaway's adaptation of The Tempest, Prospero's Books. On the other hand, it has always been the default mode of much popular cinema, where the hyperbolic actions of superheroes, the impossible monsters of fantasy, horror and sci-fi, and the carnivalesque cartoon violence of popular animation have continued ancient, even archaic narrative traditions, provoking profound forms of pleasure in audiences.

This broad tradition of the impossible image sees Méliès' paraphernalia of cardboard, costume and prop, and innovative use of lens-masks, stop-motion and multiple-exposure photography give way eventually to the prosthetics, animatronics, chroma-key, motion capture and CGI of the modern special effects industry. In semiotic terms, the best single metaphor for such work is, perhaps, lamination. Whether applied to Melies' multiple exposures, to the layering of latex in a prosthetic monster head, to the superimposition of images in matte compositing, to the filters in digital composition, or to the layering of 'skins' on wireframes in digital animation, the semiotic process is one of building-up, accretion, thickening of signifier material.

Meanwhile, the other modes in play in animated film produce other kinds of lamination. Most significantly, the mode of spoken language is separated out from physical action - these embodied modes are bifurcated in production and reunited in the edit, as the voice layer is calibrated with the visual, and in particular the lipsynced animated character.

While lamination has always been multimodal, its digital incarnation has particular properties. These include, as the children's work will show, the features of digital media expounded by Manovich (1998): the provisionality of combinations of media databases; the numerical basis of all operations; the transferability of functions across media; the work of filters, themselves a form of digital laminate.

However, while all this is of interest to semioticians and film historians, why would it be of interest in relation to children in classrooms? In the history of cinema, the role of the audience has been to listen and spectate: to be thrilled, duped, tickled, entertained, challenged. As we know, however, one consequence of the digital era has been to confer the tools of media production on the population at large, and the 
artist formerly known as 'audience' has become maker, producer, creator. This article is concerned with what children do in their own acquisition of such semiotic tools, then; and what they know about their own work: how this appears as a form of literacy, and what its cultural and curricular implications might be. The following account will briefly describe the discrete work of designing characters, sets, music and voice, before focusing in detail on the vocal performance, visual design and music of one short sequence.

\section{Character design}

The students designing characters had to determine how to represent attributes of age, ethnicity, gender and narrative function. The software makes this possible by providing menus for clothing, face type and shape, age markers, ethnicity markers (skin colour, hair), makeup, 'distinguishing features such as scars and tattoos'. While some of these are 'one-off' choices, such as a dress or a jacket, others offer tools for manipulation at a finer level of granularity. Faces, for example, can be changed through manipulation of slider tools controlling colour, shape of chin, nose, eyebrows, eyes, mouth, elements of facial expression. In this respect, designing a character resembles designing an avatar in various games and virtual worlds; and also resembles cultural practices such as doll-making and dressing for girls, both in its older scissors-and-paper form and in digital online versions.

Evidence of careful choices to create characters was plentiful. The two Bengali girls designing Cleopatra for the Dr T film were fascinated by makeup, and enjoyed making her lips a bright shade of red, before deciding that this detracted from her eyes, which should be the dominant feature. The two girls designing Jeff chose straight brown hair and a pale complexion, because he was a geek "who might play World of Warcraft, I imagine always geeky boys playing that". Figure 1 shows them developing their design, at a stage where they are making detailed choices about the character's facial features from a range of options for eyebrows. This process will be discussed in more detail as an example of digital lamination in the close-up example provided later.

\section{[INSERT FIGURE 1]}

\section{Figure 1: students composing a machinima character in Moviestorm, showing the menu for choices of eyebrows}

The boys making the set for Jeff's bedroom agreed that he might be a WoW player, and that they had put a computer on his desk which he could play it on. Neither of the girls had played WoW, though one had a brother who had. They both said they played The Sims, and described the kind of subversive practices enjoyed by players, such as building families and making them over-eat, or using the 'Die by Flies' cheat. They also described how creating Sims families resembled designing characters in Moviestorm:

- $\quad$ M: I played one Sims game and it's when you're a vet, and it's not like this but it's the same sort of basis, like you've got a character and you dress them up and you make them do stuff and make them go places. 
This process of developing a character and dressing them up indicates a particular form of game culture associated on the one hand with the systems of avatar design in online gameworlds and roleplaying games; and on the other with the cultural history of dressing dolls: actual dolls (Barbie, Action Man); or paper dolls; or online adaptations of these practices such as 'Doll Dress Makeover' (www.girlsgogames.com).

Sarita ${ }^{4}$, the girl designing the character of Lily took considerable time over the design (Figure 2). She chose a ponytail, experimented with (but rejected) multi-coloured hair, and experimented (but rejected) darker skin, although she herself was Indian. The design of the character suggests a desire for an 'everygirl', a character not marked as unusual or different, with whom spectators can easily identify. In this respect, her design resembled the design of Jeff in the other game. The children spent some time discussing exactly what kind of character he would be: how he could be a geek, but also an unlikely romantic and action hero. In his case, he clearly combines characteristic of stereotypical 'boy' genres (action, sci-fi) and 'girl' genres (romantic drama).

Sarita was also asked about games she played, and whether this resembled any of them; and cited The Sims, saying that the building of characters, homes and worlds reminded her of that experience.

\section{[INSERT FIGURE 2, SCREENSHOT OF LILY]}

\section{Figure 2: Sarita's design of Lily, the protagonist of the film}

Marco, the boy designing the 'good' werewolf Laughing Shadow in The Moonstone, was clearly excited by the exotic nature of his character, and the agonistic nature of his narrative role. He chose a scar, a tattoo, dark skin, a feather headdress, and a dark shirt and trousers. He also quickly grasped how to construct an alternative wolfface, and how the morphing from human to would work. He was sufficiently stronglymotivated to anticipate the later stage of the project by quickly editing a battle between the two werewolves. He was also asked about his experience of games, and was one of only three students who claimed a knowledge of machinima. He also declared an interest in horror film and game.

\section{[INSERT FIGURE 3, SCREENSHOT OF LAUGHING SHADOW]}

\section{Figure 3: Marco's design for Laughing Shadow, the good werewolf}

\section{Set design}

The modelling of spaces by James Durran, the media specialist teacher leading the project, showed the students how cinematic space needed to be designed with the camera in mind. It could have gaps in spaces which the camera would ignore; and it needed to leave an empty 'fourth wall', a concept the students quickly grasped. The spaces, then, had specific narrative functions: Jeff's bedroom, Ancient Egypt and a dystopian future for $\mathrm{Dr} \mathrm{T}$; and Lily's sitting room, the bar where they meet Laughing Shadow, and the forest (with crashed plane) for The Moonstone.

\section{Voice Acting}

\footnotetext{
${ }^{4}$ All children's names used in this article are pseudonyms.
} 
A significant challenge for these 11 year-olds was to represent identities of different ages, both in the words they chose and in the intonation and timbre of their voices. For example, characters in Dr T, whose dialogue was improvised by the students, are characterised by representative idioms and by accent and the children's natural vocal styles. Jeff, for example, exclaims in surprise at one point "Oh my Days", a contemporary urban expression in frequent use at this school (and in the south-east of England generally at this time). In other roles, the children needed to find appropriate characterisations. For example, the boy playing the evil alien $\mathrm{Dr} \mathrm{T}$ chose to adopt a Black urban street style, employing expressions such as 'Break it down, ladies, break it down' to intercede in a row between two other characters.

In The Moonstone, while the dialogue was scripted, the children adopted appropriate pitch, timbre, intonation and other patterns to represent the characters, such as a gruff timbre to represent adult characters: the barman and the two werewolf characters in The Moonstone.

One boy, who attended an out-of-school drama club, emphasised the importance of emotion in the voice. His role was the policeman who had to break the news to Lily of her parents' plane crash. Here, then, the resource of the dramatic voice contributed a specific element of the narrative whole, and inspired the girls who made the animation of the character to match the emotional charge of the voice with a suitable facial expression. This example is explored in more detail below.

\section{Music - affect, narrative function and character motifs}

Music was made in various ways with the composer-in-residence. Students were able to compose their own tunes for sections of the films using virtual keyboards with percussion tracks, and those who played instruments were encouraged to bring them in. Nicky described making his own tune for the Egyptian section of the Dr T film:

you put a drumbeat on, then you can make your own rhythm with the keyboard ... and then you can move the notes down after. ... It goes 'dum, dum, dum dum [sings tune]', something like that, and then you have the drumbeat, 'tch, tch', yeah, sounds quite Egyptian.

Others made digital music for the dystopian future scene; and two who played the guitar made guitar music for another scene. These two also composed the music for Cleopatra's palace, a modal four-bar loop in 4/4 with a syncopated drumbeat . Meanwhile, other members of the group recorded improvised background talk for the Egyptian market scene, representing stallholders and shoppers (see Burn, 2013, for a detailed analysis of this sequence).

\section{CLOSE-UP ON ONE SEQUENCE}

One instance from the making of the Moonstone film will serve as a detailed example of the nature of multimodal design in this project. In the completed film, it appears as the brief scene from the opening minute, in which the heroine, Lily, answers the door 
of her house to see a police officer who has the difficult task of breaking the news that her parents' plane has crashed. The processes of composition leading up to this finished sequence are revealing. The visual scene is designed by two girls, working with three sets of resources: the set design of Lily's house and the street beyond it; the characters (Lily, her friend and the policeman); and the pre-recorded voice-acting of the children playing the parts of the three characters.

The voice of the policeman is acted by a boy, who described in interview the specific function of the role:

I: what did you have to do with your voice for that part?

$\mathrm{R}$ : to make it a bit, you know, er, like you don't really want to tell her, but you have to 'cos it's your job really. Cos it's a bit upsetting to tell someone that their parents might be dead. So yeah.

I: And now you've heard it - is that the first time you've heard it with the characters speaking? Are you happy with it?

R: Er yeah. I'm fine.

...

I: what's the connection between drama and media?

$\mathrm{R}$ : Well in drama you have to use your face and your body, body language, and facial expressions: and in animated films you always also do that.

$\mathrm{He}$ is very conscious, then, of the affective charge of the vocal performance: a combination of reluctance and distress: "you don't really want to ... it's a bit upsetting ..." He relates this function to similar signification in other modes: facial expression and bodily action. His job, then, is the traditional role of the voiceover artist, which in many ways has remained unchanged in the production practices of animation since its early days. From Disney through to Pixar, voiceover acting is recorded in advance, and the animation made to fit the voice, rather than the other way round. In multimodal terms, the modes of voice and body action, unified in 'live' drama, are segregated, and put back together in post-production. The voice retains its nature as dramatic performance, an embodied realisation of character through intonation, dynamics of tempo and volume, and vocal timbre. By contrast, physical action, gesture and facial expression is of course designed visually as a simulation of performance. Nevertheless, the boy is aware of the relationship between the modes, for two reasons. Firstly, he attends an after-school drama club, and is conscious, as the interview shows, of the relationship between drama and media: that fictional narratives in film involve the same kind of embodied expression as drama. Secondly, since he is, like the girls, editing a sequence of the film with other resources, he has experienced the importance of constructing a complementary relationship between the modes.

These insights are not trivial: indeed, they have a particular significance in the pedagogy of media education. The fragmentation of the curriculum into subject domains cuts across the multimodal relationships of authentic cultural forms like film and games, and each domain tends to privilege its own modes. Media education (like film and media studies in Higher Education), is likely to emphasise the orchestrating modes of filming and editing, and to underemphasise (even neglect) important contributory modes such as dramatic action and voice. This constrained emphasis may occur in the day-to-day creative production work of teachers and 
children at least in part as a result of the conceptual frameworks they are likely to inherit from curriculum and examination designers. To make life more complicated, as I will argue later, it is not the case that such specialist expertise should be abandoned. The film educator is necessarily expert in the art of filming and editing; the music educator in melody and harmony, the drama educator in embodied action and voice. It is a question of how each can become sufficiently aware of each other's domain, sufficiently collaborative at the right moment, and sufficiently creative in overcoming subject domain silos when necessary.

In terms of the boy's vocal performance, he delivers the lines with appropriate choice of intonation, volume and pace. Although the lines are scripted, he introduces three hesitation indicators: "um", a repetition of "I've", and a pause (Table 1, Shot 3).

To return to the sequence of composition in the film, we can see how the girls have constructed the sequence as four shots (Table 1 ).

\begin{tabular}{|c|c|c|c|c|c|c|}
\hline Shot & $\begin{array}{l}\text { Framing and } \\
\text { camera }\end{array}$ & Action & Speech & Gesture & Face & Music \\
\hline 1 & $\begin{array}{l}\text { Mid two-shot } \\
\text { (Lily and } \\
\text { friend)from } \\
\text { behind Lily }\end{array}$ & $\begin{array}{l}\text { Lily goes } \\
\text { to open } \\
\text { door }\end{array}$ & & $\begin{array}{l}\text { Door } \\
\text { opens }\end{array}$ & $\begin{array}{l}\text { (Back of } \\
\text { head) }\end{array}$ & $\begin{array}{l}\text { Guitar and } \\
\text { bass loop }\end{array}$ \\
\hline 2 & $\begin{array}{l}\text { Close-up two- } \\
\text { shot (Lily and } \\
\text { officer) from } \\
\text { behind Lily }\end{array}$ & $\begin{array}{l}\text { Lily opens } \\
\text { door, } \\
\text { revealing } \\
\text { officer }\end{array}$ & $\begin{array}{l}\text { Officer: } \\
\text { "Is one of } \\
\text { you Lily } \\
\text { Woods?" } \\
\text { Lily: "Yes, } \\
\text { that's me" }\end{array}$ & $\begin{array}{l}\text { Officer } \\
\text { waves } \\
\text { right arm }\end{array}$ & $\begin{array}{l}\text { Officer's } \\
\text { face } \\
\text { neutral }\end{array}$ & $\begin{array}{l}\text { Solo violin } \\
\text { descending } \\
\text { minor } \\
\text { arpeggios }\end{array}$ \\
\hline 3 & $\begin{array}{l}\text { Extreme } \\
\text { Closeup } \\
\text { (officer's } \\
\text { face); camera } \\
\text { pulls back to } \\
\text { closeup (head } \\
\text { and } \\
\text { shoulders) }\end{array}$ & $\begin{array}{l}\text { Officer } \\
\text { gives the } \\
\text { news }\end{array}$ & $\begin{array}{l}\text { Officer: } \\
\text { "Well, um, } \\
\text { l've, l've } \\
\text { come to } \\
\text { tell you } \\
\text { that } \\
\text { [pause] } \\
\text { the plane } \\
\text { that your } \\
\text { mum and } \\
\text { dad were } \\
\text { on has } \\
\text { crashed, } \\
\text { or has } \\
\text { gone } \\
\text { missing - } \\
\text { " }\end{array}$ & $\begin{array}{l}\text { Officer } \\
\text { bows } \\
\text { head and } \\
\text { raises it } \\
\text { again }\end{array}$ & $\begin{array}{l}\text { Officer's } \\
\text { eyebrows } \\
\text { raise in } \\
\text { the } \\
\text { centre, } \\
\text { eyes } \\
\text { widen. }\end{array}$ & $\begin{array}{l}\text { Violin } \\
\text { continues } \\
\ldots\end{array}$ \\
\hline 4 & $\begin{array}{l}\text { Mid two-shot } \\
\text { reaction (Lily } \\
\text { and friend) }\end{array}$ & $\begin{array}{l}\text { Lily } \\
\text { weeps, } \\
\text { comforted } \\
\text { by friend }\end{array}$ & $\begin{array}{l}\text { "- over } \\
\text { the } \\
\text { National } \\
\text { forest". }\end{array}$ & $\begin{array}{l}\text { Lily } \\
\text { covers } \\
\text { face; she } \\
\text { and friend } \\
\text { turn to }\end{array}$ & $\begin{array}{l}\text { Lily's } \\
\text { eyebrows } \\
\text { raise; } \\
\text { mouth } \\
\text { turns }\end{array}$ & $\begin{array}{l}\text { Violin } \\
\text { continues } \\
\ldots\end{array}$ \\
\hline
\end{tabular}




\begin{tabular}{|l|l|l|l|l|l|l|}
\hline & & & $\begin{array}{l}\text { each } \\
\text { other }\end{array}$ & down. & \\
\hline
\end{tabular}

\section{TABLE 1: multimodal analysis of Lily and the Policeman}

In interview, the girls describe the process of making the scene.

I: Now you've looked at the scene, what have you changed?

R1: we did a lot more of the camera and a lot more of the expressions and moods and stuff.

I: Can you give some examples of that?

R1: um, well, when the policeman was telling Lily that her parents had gone missing then he was just like standing there with a really straight face and just saying sort of "I'm sorry your parents have gone missing" [in monotone]. ... and then we had to, we went on the mood bit [makes gesture of sliding from left to right] and then we, cos there's only like a few bits like sad, angry, and happy, romantic and stuff, went on the advanced one and we made him more happy and more sort of, with the wiggly faced one -

I: How do you do that?

R1: cos if you go on the advanced and then it's got these ones with er sliders [makes gestures outlining the functions box and the slider] and you can slide up which emotion you want them to have more of and which less.

$\mathrm{I}$ : and how does that fit with the voice?

R1: Yeah, it's really good, cos when he's looking down and he's all sort of sad that it's happened, he's feeling sorry for Lily.

R2: and the voices make it sound realistic, cos if you didn't have the voice recorded it would sound like a robot.

I: And now you look back on it, what are you most happy with?

R1: I think that policeman bit was really really good, cos his expression completely fitted in with when he was looking down and what, what the voice was saying. That was probably the best bit.

The compositional process has begun, then, with the designing of assets as described above. Another student has been responsible for building Lily and the police officer, progressing through the layers of composition in Moviemaker to construct face shape, hair, eyes, eyebrows, nose, mouth, clothing and so on. The job of the girls here is to build the moving image sequence on the editing track of the software: organise it into shots by inserting cut points, reframing the image with a virtual camera to change point-of-view, shot distance, angle, camera movement, and deciding how to represent actions and speech: which character to show when, and how. In many ways, this orchestrating work of the mode of editing is similar to such work in conventional film. It involves, for example, learning the purpose and structure of shot-reverse-shot sequences to represent conversation, as the other group in the project learned (Burn, 2014).

However, the nature both of machinima and of this particular authoring tool, Moviestorm, produces some differences both from live action film and from conventional animation. As the transcript shows, the girls viewed the sequence in the rough edit of the whole film, and noticed that the policeman's expression did not convey the appropriate sentiment for his words. Interestingly, they convey this 
shortcoming of the visual design by reciting his words in a monotone, a form of intermodal transduction (Kress, 2010), even though, as we shall see, the vocal expression in the audio track does enact the affective charge of the words. In any case, aware of the mismatch between the modes, they amend the facial expression of the police officer, going into the relevant Moviestorm menus to find the slider tools to change the eyes, mouth and eyebrows.

In terms of the kineikonic mode, this piece of compositional redrafting is distinctively digital. It would not be possible in live action film without re-shooting part of the scene; nor in cel animation without redrawing the cels. Nor would it be possible in conventional machinima without re-enacting the sequence with the virtual actors in the virtual world. However, the machinima here is really a blend of machinima and 3$D$ animation, and has the options of 3-D animation to rework the character on the fly, digging through the laminates to the layers that need adjusting. In semiotic terms, it consists of reworking the kineikonic syntagm through paradigmatic substitution, making a closer intermodal match between the sorrowful intonation of the vocal track and the relevant parts of the facial expression (Figure 4). There is a selection of paradigmatic elements in play: replacing, in this child's words, "straight" with "all sort of sad", bypassing a simple repertoire of "sad, angry, and happy, romantic and stuff", and working with a finer granularity of individual features. Such adjustments have similarities to the adjustment of lighting, audio volume, shot angle and so on in the semiotics of film, in that they are distributed across a numerical scale. The film semiotician Christian Metz argued that such elements could not properly be considered part of the 'grammar' of film, since they were continuous scales rather than paradigmatic elements (Metz, 1974). However, we may dispute this because of the perceptions of the human sign-makers, and the ways in which they realise degrees of the scale in language. This produces something more like paradigmatic choices: camera angles, though adjustable on a continuous scale, become low shot, high shot, bird's-eye shot, and so on. Lighting becomes high or low, hard or soft, top or below, key, fill or back. Similarly, in these girls' choices, the slider scale filter for the policeman's eyebrows represents choices between neutral and sad.

\section{INSERT FIGURE 4: THE POLICEMAN}

\section{Figure 4: the girls' design of the policeman}

Another point is worth mentioning. Since this is a digital medium, all choices at one the level resolve into numerical ones. As Manovich points out, this is one of the true distinguishing features of digital media (Manovich, 1998). However, once again, in terms of the interest of the signmaker (Kress and van Leeuwen, 1996), this numerical scale is transformed into paradigmatic choice. The child is not interested in the number, or even aware of it (though if the learning objectives here were focused on computer science, she might be). She is only interested in manipulating the representation of affect, and making a match between the modes of speech and virtual embodiment. In cultural terms, as noted above, we can see that the analogies are with similar activities in previously encountered virtual worlds which children have engaged with, such as The Sims, and, as Marsh observes, a range of other online virtual worlds including Club Penguin, Neopets, Moshi Monsters, and Habbo Hotel (Marsh, 2014). 
In the context of the history of the moving image, as I have argued above, these practices evolve from a different source than the emergence of film from stage drama, or the conception of film as a documentary record of 'real' life. Rather, the culture and practice of animation in early cinema, best-known in the work of Georges Méliès, derives from traditions of illusion, magic, 'trick' photography, and their associated practices of overlay, lamination, filtering and deceptive use of light.

In these children's machinima film, these practices are still apparent. The appeal of animation is its readiness to represent the 'impossible image': fantasy elements of werewolf transformation, science fiction, time travel, and videogame play between virtual and 'real' life.

The final layer to consider is the music layer. This was composed by another group, using acoustic guitar, synthesised electric bass, and violin. The first sequence, which begins the film, continues through Lily and Kelly's conversation, and stops when Lily opens the door at the end of Shot 1, is a repeated two-bar finger-picked ostinato, or repeated melodic pattern, with a bass line that suggests minor chords and at one point (bar 2) a discord. The use of ostinato in film music is ambiguous: on the one hand, it can provide a dynamic, driving, insistent quality; on the other hand it can stabilise, even lead to monotony. This ambiguity is well-suited to this scene: nothing out of the ordinary is happening yet, so the scene is in this sense stable; yet we are made aware of an impending crisis. The effect is of muted disquiet, appropriate for the dramatic mood of the piece, and anticipatory of the bad news to come (Figure 5).
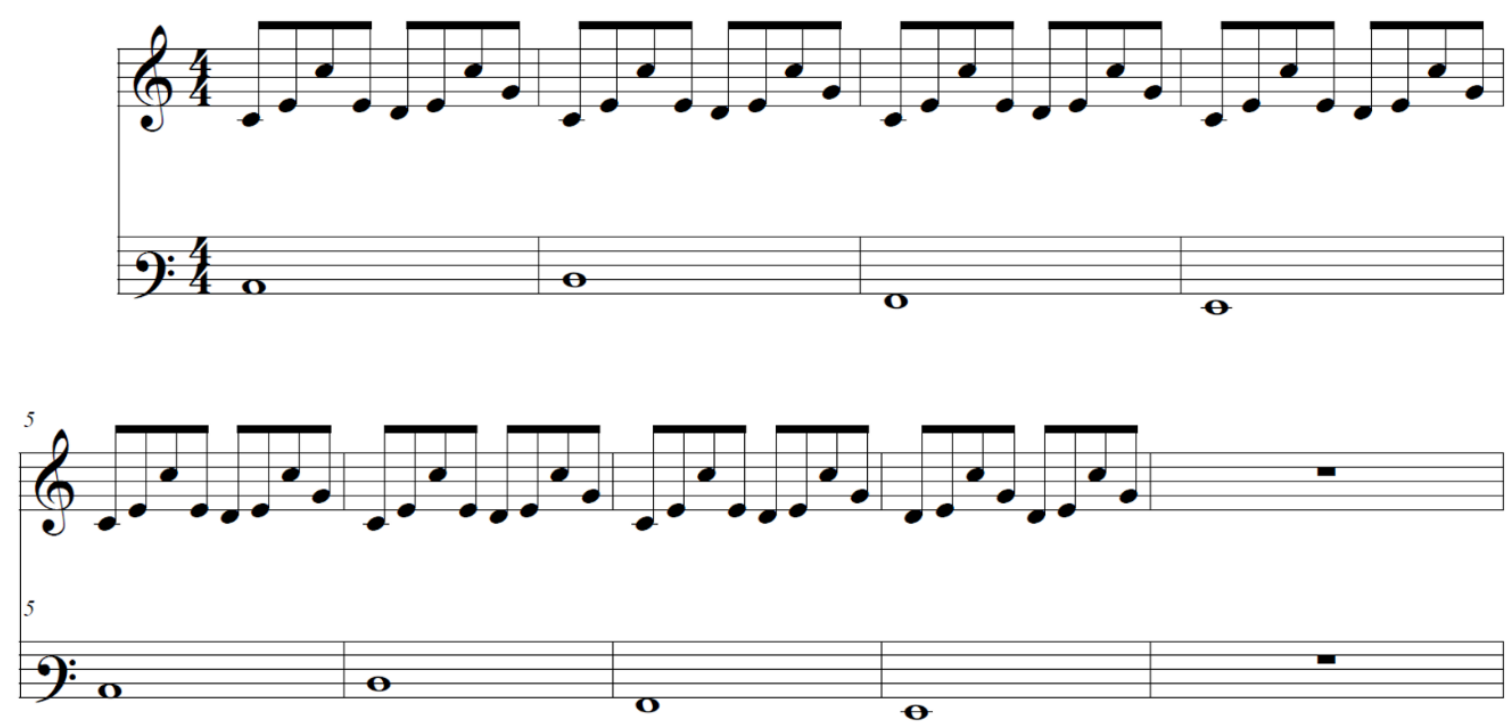

Figure 5: the ostinato sequence accompanying Shot 1

The second sequence, which begins as the policeman starts speaking, is a soulful descending series of notes in a minor key, played on a solo violin. Minor keys traditionally signify sadness, of course: while the melodic descent happens in steps: each bar descends, rises a little in the successive bar before descending further, and 
so on, so that an effect of a struggle against descent is conveyed. It has a baroque quality, accentuated by a trill on the penultimate note, a typical ornament of the baroque, suggestive of emotion (as in the music of Bach) (Figure 6). Here, the clear intention is to convey the tragic quality of the policeman's message.
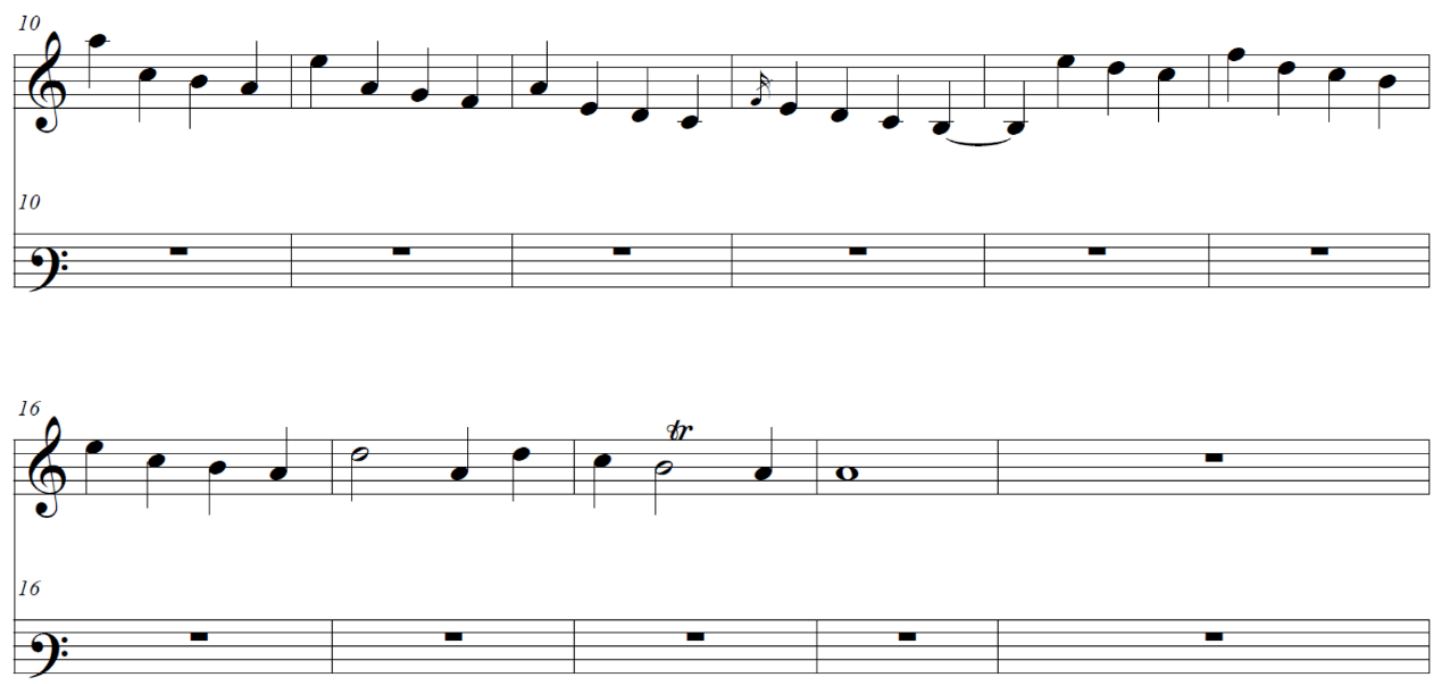

\section{Figure 6: the solo violin sequence accompanying shots 2-4}

The music as contributory mode is performing a range of functions in this sequence. The loop structure of the ostinato in the first section is reminiscent of videogames and the unpredictable duration of their game-play sequences. It also indicates, in its uncertain oscillation between major and minor, the tension between the girls' ordinary evening at home and the growing anxiety caused by the parents' lateness.

The abrupt shift into the tragic, legato (smoothly-flowing) scales of the violin clearly complements the emotional charge of the policeman's message. Here, the tonality of the violin, the downward trajectory of the descending arpeggios, and the minor key all work to emphasise through the mode of music the representations carried by the vocal characteristics of the boy's performance, and the linguistic elements of the policeman's message.

This layer is added in the edit, not by the girls, but by the composer-in-residence, Joel. While the compositional work and the performance is by the children, then, the adult participates in the composition of the film. There are two ways to consider such participation. Arts projects in schools can be justly criticised for excessive adult intervention in the creative process. On the other hand, they can be seen as legitimate collaborators, partners in the creative process: as long as the children have significant, even perhaps dominant roles in that process. In this case, the children have written the story, made all the multimodal assets, edited the visual sequences and made most of the creative decisions. The roles of the adults have been to guide, shape, encourage, support technical processes, and teach principles of moving image composition.

This detailed analysis of the specific layers of vocal performance, visual design and music composition reveals two orientations in terms of the semiotics of the moving image and its 'technologies of inscription', or material media (Kress and van Leeuwen, 1996). One orientation is towards the traditional lamination processes of 
animation, as discussed in the earlier sections of this article: the bifurcation of vocal and bodily performance; the layering of visual imagery to produce the 'impossible image'; and we have also seen the additional layer of musical signification, common to all forms of moving image media since their inception. The other orientation is towards the 'language of new media': to the digital laminates of filters, the numerical scales of image adjustment and the new paradigmatic choices they produce; and to the playful compositional regimes of videogames and virtual worlds. We have also seen how this mix of practices requires the collaboration of educators with different specialisms across the arts: drama, literacy, music, media education, ICT.

\section{CONCLUSIONS: Montage, Mash-up, Machinima}

How, then, does this project help us with with the three questions outlined at the beginning of this article? What changes in film culture, in the semiotic work of the moving image, and in the curriculum structures supporting film and media education, can be found, and what is their value for educators?

In cultural terms, my view is that such a project offers a bridge between the wellestablished traditional cultural practices of film, and the media cultures of young people. In respect of the former, film studies teachers might be reassured to know that a cultural form like machinima, which might seem disturbingly unfamiliar to many film specialists, can be located in a tradition of animation which begins with Melies and incorporates European art animation as well as popular Hollywood cartoons. At the same time, they might need to extend their awareness of animation as a feature of videogame design, and of the representational practices players are able to make through their own world-building (from The Sims to Minecraft) and avatar customisation (from Club Penguin to World of Warcraft).

In terms of multimodal semiotics, again there is a good deal here that would be quite recognisable in the traditional creative production work of film and media studies classrooms. In particular, the focus on the familiar features of the editing timeline: ordering, camera angle, distance and movement, shot transition - these features of the orchestrating modes of filming and editing are well-known from a hundred filmmaking and film-studies textbooks, and it is clear that, whatever the novel features of the digital medium and the new form of machinima, they depend equally upon the century-old grammar of the moving image. Similarly, this new animation continues, as we have seen, in the practices of lamination central to the 'impossible image' of animation from its birth. Again, however, educators need to consider, recognise and exploit the new features: the new kinds of lamination offered by digital filters; the scalar adjustments of character and set design; the digital puppetry involved in constructing dramatic action.

Finally, in terms of curricular provision, this project demonstrates the importance of connecting children's understanding of processes of representation and their creative practice across the range of what school curricula constitute as distinct disciplines: in this case, literacy, media education, music, art and ICT. The argument here for 'connected learning' (Sefton-Green, 2014) needs also to be aligned with the ways in which the specificities of media literacies can be related to more general understandings of learning in the field of education (Drotner and Erstad, 2014). But it 
is also a question of where media education situates itself. The productive tension between heritage culture and popular culture which characterises film education, as discussed at the beginning of this article, is replicated in various ways in the other arts. In this sense, the project described here, drawing both on century-old traditions of animation and on the new popular form of machinima, occupies similar cultural territory, suggesting closer collaboration across the arts in education. Meanwhile, the educators in the projects have collaborated fruitfully, again suggesting how the different pedagogies of the arts can complement each other, developing visual design, embodied performance, musical composition ensemble work, and editing practices.

In general terms, then, the project described here is in many ways an example, not of disjuncture or radical practice, but of bridge-building. The most promising way to advance the cause of media education may be to recognise the continuities between traditional forms of creative practice, literacy and cultural form (in film and literature, for example), and the new cultural dispositions of children's media practices, the new genres of the moving image characteristic of the participatory internet and mashup culture, and the specific semiotic features of the established compositional practices of the moving image and its more recent transformations. My hunch is that Melies would have been at home in the forms of lamination typical of 3-D animation; and the best hope for media education is to build bridges between old and new. Meanwhile, another kind of mash-up occurs: between the distinctive pedagogies of the arts, and the forms of social meaning-making they enable, along with the technologies they shape and are shaped by.

\section{REFERENCES}

Barthes, R (1978)'The Third Meaning', in Image-Music-Text, translated by Stephen Heath, New York: Hill and Wang

Bordwell, D and Thompson, K (2001) Film Art: an Introduction (6th edition), New York: McGraw-Hill

Buckingham, D (2003) Media Education: Literacy, Learning and Contemporary Culture, Cambridge: Polity

Burn, A (2013) 'The Kineikonic Mode: Towards a Multimodal Approach to Moving Image Media'. In Jewitt, C (2013) The Routledge Handbook of Multimodal Analysis, $2^{\text {nd }}$ edition. London: Routledge.

Burn, A and Durran, J (2007) Media Literacy in Schools: practice, production and progression. London: Paul Chapman

Burn, A and Parker, D (2003) Analysing Media Texts, London: Continuum

Drotner, K and Erstad, O (2012) 'Inclusive Media Literacies: Interlacing Media

Studies and Education Studies' International Journal of Learning and Media, Spring 2012, Vol. 4, No. 2, Pages 19-31

Gibbons, D. (2010). Tracing the paths of moving artifacts in youth media production. English Teaching: Practice and Critique, 9(1), 8-21.

Kelland, M., Morris, M., and Lloyd, D. (2005). Machinima, London: Course

Technology PTR.

Kress, Gunther (2010). Multimodality: A Social Semiotic Approach to Contemporary Communication. New York: Routledge.

Kress, G and van Leeuwen, T (1996) Reading Images: the Grammar of Visual

Design. London: Routledge. 
Manovich, L (1998) The Language of New Media, Cambridge MA: MIT Press.

Marsh, J. (2014). Purposes for literacy in children's use of the online virtual world 'Club Penguin'. Journal of Research in Reading. Volume 37, Issue 2, pages 179195, May 2014.

Metz, C (1974) Film Language, Chicago IL: Chicago University Press

Potter, J (2012) Digital Media and Learner Identity: the New Curatorship. London:

Palgrave Macmillan.

Reid, M, Burn, A, Wall, I (2012) Screening Literacy: film education in Europe. London: British Film Institute.

Sefton-Green, J (2014) 'Innovative methods for researching connected learning:

Introduction'. International Journal of Learning and Media Spring, 2012, Vol. 4, No.

2: $1-5$ 